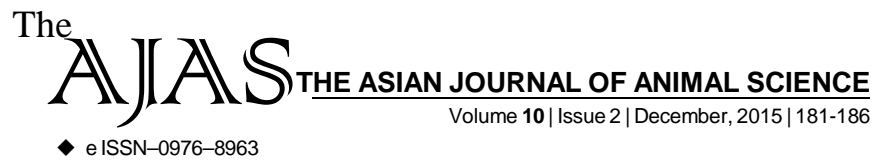

DOI : 10.15740/HAS/TAJAS/10.2/181-186 Visit us | www.researchjournal.co.in $\mathbf{S}$

RESEARCH ARTICLE.

\title{
Effect of optimum dietary supplementation of vitamin C on the body performance parameters of poultry and in combating heat
} stress

\author{
AMIT KUMAR, BARUN ROY, PRAVEEN KUMAR PRAVEEN, SUBHA GANGULY, SHASHANK \\ SHEKHAR AND NIRUPAMA DALAI

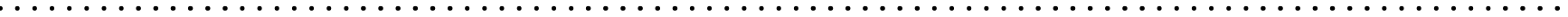

Author for Corresponding -

\section{SUBHA GANGULY}

Department of Veterinary

Microbiology, Arawali Veterinary

College, Bajor, SIKAR

(RAJASTHAN) INDIA

Email: ganguly38@gmail.com

See end of the article for

Coopted authors'
ABSTRACT...... Supplement of vitamin C in different sources may have some important in production of commercial broiler chicken to reach better growth and performance supplementation of vitamin $\mathrm{C}$ may have some influence to combat stress to environmental temperature and humidity to study the effect of different sources of vitamin $\mathrm{C}$ viz., Him $\mathrm{C}$ (Herbal supplementation, of vitamin C) Limcee A synthetic ascorbic acid source and Amla natural source of vitamin $\mathrm{C}$ was taken in different treatment group on commercial broiler chicken, four hundred twenty days old commercial broiler chicks of Vencobb 400 strain of both sexes were randomly divided into four groups (one control and three treatment). The experimental group were CS1 (Fed controlled that without vitamin C supplementation) TS (Fed controlled diet with Him C), TS 2 (Fed control diet with Limcee) and $\mathrm{TS}_{3}$ (Fed controlled that with dried Amla). The trail was conducted under field condition for forty two days. From the present study it was concluded that the supplementation of dried Amla @ 185g/ton of feed showed better performance in term of live weight gain compared to supplementation of Him $\mathrm{C}$ and synthetic ascorbic acid, respectively.

KEY WORDS...... Body performance, Chicken, Vitamin C

HOW TO CITE THIS ARTICLE - Kumar, Amit, Roy, Barun, Praveen Kumar Praveen, Ganguly, Subha, Shekhar, Shashank and Dalai, Nirupama (2015). Effect of optimum dietary supplementation of vitamin $\mathrm{C}$ on the body performance parameters of poultry and in combating heat stress. Asian J. Animal Sci., 10(2): 181-186.

ARTICLE CHRONICLE - Received : 21.08.2015; Revised : 16.11.2015; Accepted : 21.11.2015 